\title{
Enhancement of Specific Power Output of a Gas Turbine Using Filtered Chilled Air
}

\author{
S. Suneetha and A. V. Satyanarayana \\ Dept., of Mechanical Engineering G. Pulla Reddy Engineering College. Kurnool-518007
}

\begin{abstract}
Conventionally the specific power output of the gas turbine can be increased using reheating and intercooling. The thermal efficiency can be improved by adding a regenerating at lower pressure ratios. In the present work the emphasis is given to enhance the specific power output by other means like reduction in the air temperature at the inlet duct. The power output of the gas turbine has been estimated by allowing air at reduced temperatures, step wise. The experiment is conducted till STP conditions are attained. The chiller coils are used for inlet air cooling. The variation of power output with respect to temperature is also studied.

Keywords: Gas turbine, Inlet air cooling, cooling coil arrangement.
\end{abstract}

\section{Gas Turbine Cycle with Cooling System}

\section{Introduction}

The gas turbine is an internal combustion engine that uses air as the working fluid. The engine extracts chemical energy from fuel and converts it to mechanical energy using the gaseous energy of the working fluid (air) to drive the engine and propeller, which, in turn, propel the airplane. The basic principle of the airplane turbine engine is identical to any and all engines that extract energy from chemical fuel. In the case of a piston engine, such as the engine in a car or reciprocating airplane engine, the intake, compression, combustion, and exhaust steps occur in the same place (cylinder head) at different times as the piston goes up and down. In the turbine engine, however, these same four steps occur at the same time but in different places. As a result of this fundamental difference, the turbine has engine sections called: 0.The inlet section, 0.1Air filter section, 0.2 Cooling system, 0.3 the compressor section, 0.4 the combustion section (the combustor), 0.5 the turbine (and exhaust) section.

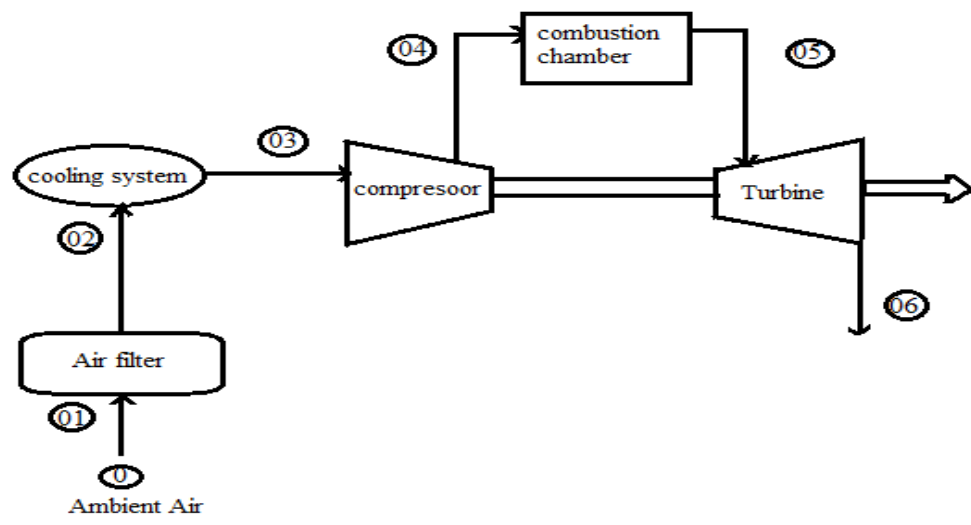

Figure 1: Gas Turbine Cycle with Cooling System

The turbine section of the gas turbine engine has the task of producing usable output shaft power to drive the propeller. In addition, it must also provide power to drive the compressor and all engine accessories. It does this by expanding the high temperature, pressure, and velocity gas and converting the gaseous energy to mechanical energy in the form of shaft power. A large mass of air must be supplied to the turbine in order to produce the necessary power. This mass of air is supplied by the compressor, which draws the air into the engine and squeezes it to provide high-pressure air to the turbine. The compressor does this by converting mechanical energy from the turbine to gaseous energy in the form of pressure and temperature. 


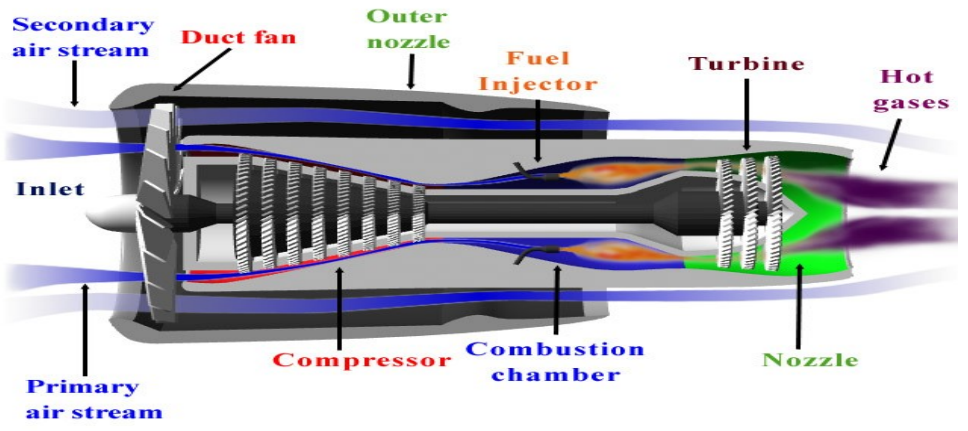

Figure 2: Gas Turbine Internal Arrangement

The relative motion of the blades to the fluid adds velocity or pressure or both to the fluid as it passes through the rotor. The fluid velocity is increased through the rotor, and the stator converts kinetic energy to pressure energy. Some diffusion also occurs in the rotor in most practical designs. The increase in velocity of the fluid is primarily in the tangential direction (swirl) and the stator removes this angular momentum. The pressure rise results in a stagnation temperature rise. For a given geometry the temperature rise depends on the square of the tangential Mach number of the rotor row. Current turbofan engines have fans that operate at Mach 1.7 or more, and require significant containment and noise suppression structures to reduce blade loss damage and noise.

\section{Inlet Air Cooling}

A chilling system for gas turbine inlet air is a beneficial option for installations where high ambient temperatures are common. With inlet air cooling a gas turbine will have a higher mass flow rate and pressure ratio, yielding an increase in turbine output power and efficiency. With a chilling system, a chilling coil is inserted in the filter house downstream of the filtering elements, in the clean air path. Downstream from the coils, a mist eliminator is installed in order to prevent condensed water droplets from entering the gas turbine inlet duct. The chiller coil cooling fluid is usually a mixture of water and glycol to avoid freezing in the coil tubes. The economic benefit of chilling system is directly related to the potential average increase in annual output, and this in turn is dependent on average ambient conditions. A chilling system can be installed on any gas turbine. In a chilling system, heat is removed from the inlet airflow by means of heat exchangers (chilling coils). Cooling is achieved through both sensible cooling (no condensation of water) and latent cooling (with condensation of water), where the former is more energy efficient but the air is only cooled down to the dew point. Figure 3 Inlet Air Cooling Process

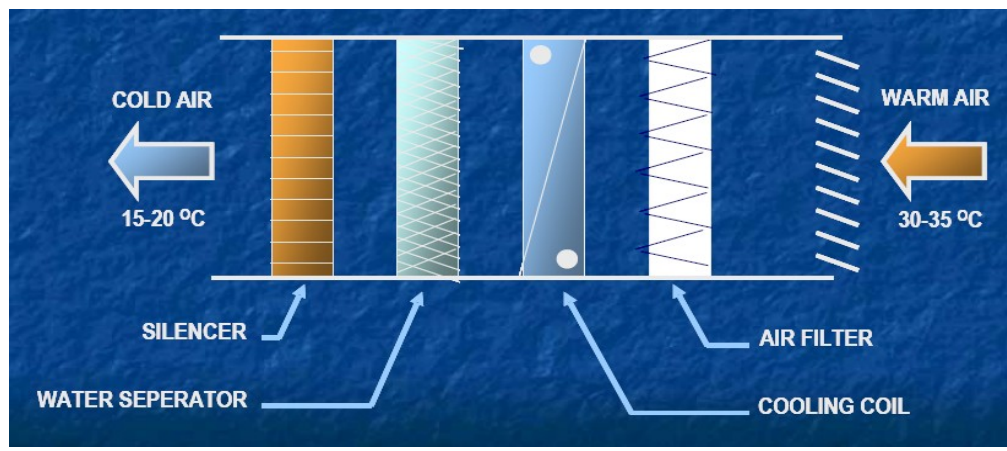

Figure 3: Inlet Air Cooling Process

The cooling should be limited to $8^{\circ} \mathrm{C}$ due to the risk of ice formation on the Inlet Guide Vanes (IGV). Therefore, a control valve should be installed on the adduction header in order to provide the chilling system with the required turndown capability. The following images show the approximate water condensation rate and the required refrigeration duty on the coolant side. The coolant supplied to the heat exchangers can be supplied by several methods, including mechanically actuated refrigeration cycles (e.g., propane cycles), absorption chillers, and ice storage systems. In the example provided, the cooling would have an effect of up to a $22 \%$ increase in power and a reduction in heat rate of as much as $6.5 \%$, even considering the additional 1 inch of $\mathrm{H}_{2} \mathrm{O}$ pressure loss introduced by the coils and the mist eliminator. The actual power increase may be limited so as not to exceed the driver and driven equipment ratings. The effect of 1 inch of $\mathrm{H}_{2} \mathrm{O}$ permanent inlet pressure loss has to be taken into account when the unit operates with the chiller off. 

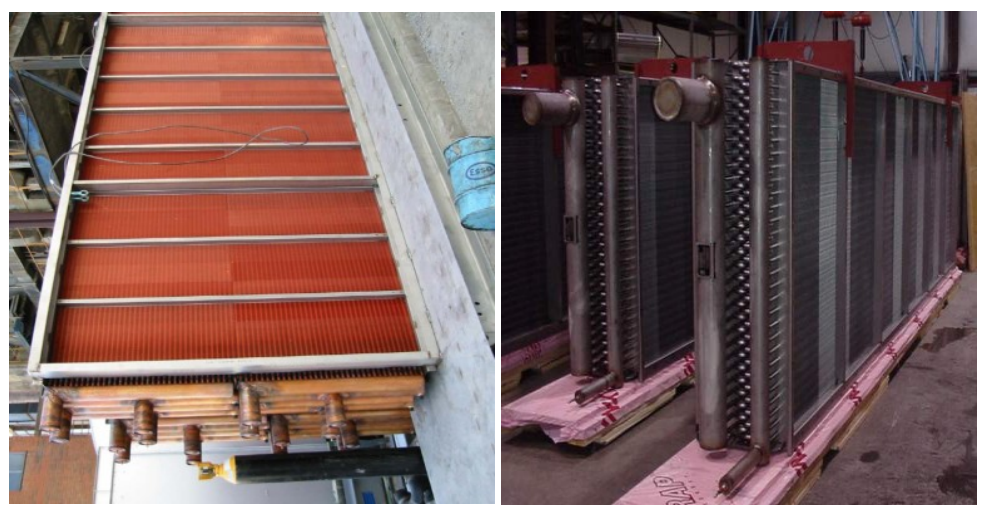

Figure 4: Arrangement of Cooling Coils

The chilling coils are normally placed downstream of the filter cartridges in the clean-air path inside the filter house itself. This will result in a zero fouling factor for the chilling coils and a reduction of maintenance requirements. A mist eliminator is provided downstream of the coils to prevent condensed water droplets from entering the inlet duct and causing erosion or FOD damage to the axial compressor. Moreover, the transition duct between the filter house and the inlet duct is symmetrical in order to ensure flow uniformity over the surface of the coils. This feature, together with the placement of the coils inside the filter house, ensure an airflow speed over the surface of the coils low enough to avoid the risk of water carry-over.

\section{Working Principal of chiller coil}

As airflow passes through the chilled coils, the air is cooled through an indirect heat exchange with the cooling fluid. The air then passes through drift eliminator media and into the turbine. The coils are cold and therefore condensation is created. Condensate droplets are directed downward and collected in pans, then directed out of the system. Typically, all condensation is eliminated this way, but to ensure air dryness, mist eliminator panels are in place to remove any stray condensate droplets.
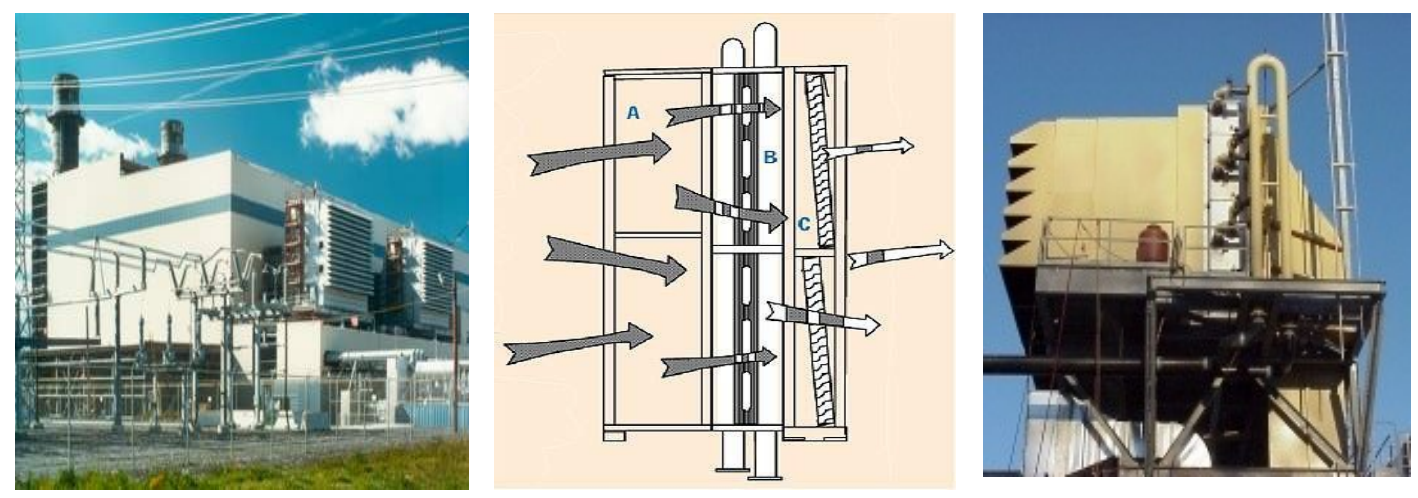

Figure 5: Chiller Coil Systems

\section{Chiller System Components}

(A) Access Module: Provides access so operators can check systems functionality and perform repairs should they be necessary.

(B) Chiller Coil Section: Chiller coil tubes are typically made of copper and caged with aluminum fins that economically and effectively extend the cooling surface area. Coil casings are stainless steel for long life.

Supply and return manifolds distribute incoming water evenly to individual coil headers so that all coils cool the airflow to the same temperature. When moist air is cooled below the wet bulb temperature, condensation forms. Condensate is collected in stainless steel drip pans and directed out of the system.

(C) Drift Panels: A final preventive measure, drift eliminator panels prevent any remaining condensate droplets from going into the ducting. Moisture removed by the drift eliminator panels is drained into the sump at the bottom of the unit.

\section{Results}

It can be seen from the graph that with increase in inlet air temperature the power output decreases and heat rate increases. As the inlet air temperature increases the density of air decreases resulting in reduced mass flow of air. This reduced mass flow air leads to reduction in power output and increase in heat rate. As we know the power output from a gas turbine is dependent on the air flow and the enthalpy expended in the turbine. As 
the mass flow of air in the turbine reduces the capacity of the gas turbine to consume fuel also decreases, since the firing temperature is fixed. The reduction in the fuel also leads to reduced

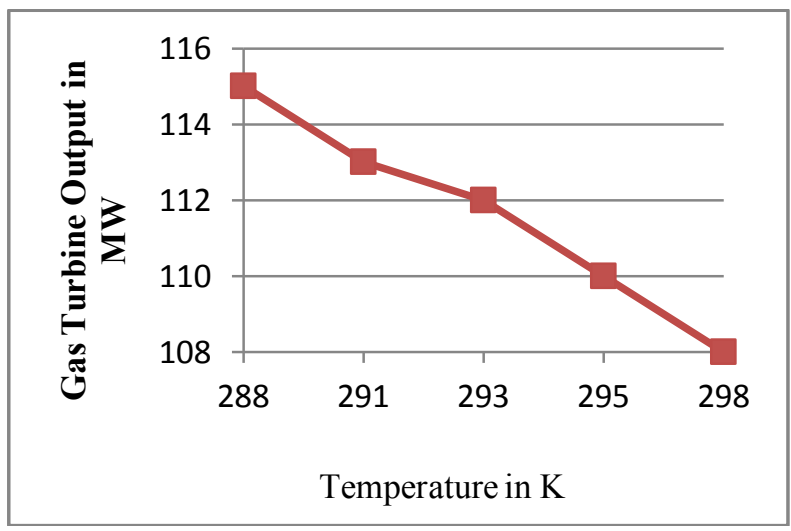

Figure 6: Effect of Inlet Air Temperature on Gas Turbine Power Output

Table 1: Calculations for Chiller Capacity

\begin{tabular}{|c|c|c|c|}
\hline Temperature in ${ }^{\circ} \mathrm{C}$ & Chiller Capacity in TR & $\begin{array}{c}\text { Gas Turbine Power } \\
\text { Output in MW }\end{array}$ & $\begin{array}{c}\text { Approximate cost @ } \\
0.45 \text { lakhs/Ton }\end{array}$ \\
\hline 33 & & 102.19 & 290 \\
\hline 25 & 643.3352 & 107.9 & 701 \\
\hline 22 & 1558.041 & 110.04 & 1,276 \\
\hline 20 & 2835.147 & 111.47 & 1,630 \\
\hline 18 & 3621.67 & 112.8 & 2,123 \\
\hline 15 & 4717.452 & 114.94 & \\
\hline
\end{tabular}

\section{Conclusions}

- Using air at atmosphere pressure and temperature gas turbine produces power of 102.19MW. But when cold air at STP is used the turbine output increases to $114.94 \mathrm{MW}$.

- Hence percentage increases in turbine is $12.47 \%$.

- Air is cooled from $33^{\circ} \mathrm{C}$ to $15^{\circ} \mathrm{C}$ using chiller. Under this condition chiller capacity is $4717.45 \mathrm{TR}$.

\section{Bibliography}

[1] Farzaneh-Gord, M.; Deymi-Dashtebayaz, M. Effect of various inlet air cooling methods on gas turbine performance. Energy, 36, 1196-1205, 2011.

[2] ASHRAE. ASHRAE Handbook - HVAC Systems and equipment (SI). Atlanta, 2008.

[3] Al-Ibrahim A. M.; Varnham, A. A review of inlet air-cooling technologies for enhancing the performance of combustion turbines in Saudi Arabia. Applied Thermal Engineering, 30, 1879-1888, 2010.

[4] Amell, A. A.; Cadavid, F. J. Influence of the Relative Humidity on the Air Cooling Thermal Load in Gas Turbine Power Plant. Applied Thermal Engineering, 22, 1529-1533, 2002.

[5] Ibrahim, T. K.; Rahman M. M.; Abdalla A. N. Improvement of gas turbine performance based on inlet air cooling systems: A technical review. International Journal of Physical Sciences, 6 (4), 620-627, 2011.

[6] Jaber, Q. M. Jaber, J. O.; Khawaldah, M. A. Assessment of power augmentation from gas turbine power plants using different in let air cooling systems. Jordan Journal of Mechanical and industrial Engineering, 1(1), 7-15, 2007.

[7] Alhazmy, M. M.; Najjar, Y. S. H. Augmentation of gas turbine performance using air coolers. Applied Thermal Engineering, 24,415-429, 2004.

[8] Nasser, A. E. M.; El-Kalay, M. A. A heat-recovery cooling system to conserve energy in gas-turbine power stations in the Arabian Gulf. Applied Energy, 38 (2), 133-142, 1991.

[9] Dawoud, B.; Zurigat Y. H.; Bortmany, J. Thermodynamic assessment of power requirements and impact of different gas-turbine inlet air cooling techniques at two different locations in Oman. Applied Thermal Engineering, 25, 1579-1598, 2005.

[10] Hosseini, R.; Beshkani, A.; Soltani, M. Performance improvement of gas turbines of Fars (Iran) combined cycle power plant by intake air cooling using a media evaporative cooler. Energy Conversion and Management, 48, 1055-1064, 2007.

[11] Brooks, F. J. GE Gas turbine performance characteristics. GE Power Systems. Schenectady, NY. GER -3567H.

[12] Mahmoudi SM, Zare V, Ranjbar F, Farshi L (2009). Energy and exergy analysis of simple and regenerative gas turbines inlet air cooling using absorption refrigeration. J. Appl. Sci., 9(13): 2399-2407. 